\title{
Electrochemical Detection of Dopamine and Tyrosine using Metal oxide (MO, M=Cu and Ni) Modified Graphite Electrode: a Comparative Study
}

\author{
Budde Kumara Swamy ${ }^{1}$, Kudekallu Shiprath ${ }^{1}$, K. Venkata Ratnam ${ }^{1}$, H. Manjunatha ${ }^{1 * \mathbb{C}}$, Sannapaneni \\ Janardan 1, A. Ratnamala 1, K. Chandra Babu Naidu ${ }^{2}$ (D), S. Ramesh ${ }^{2}$, Kothamasu Suresh Babu ${ }^{3}$ \\ 1 Department of Chemistry, GITAM School of Sciences, GITAM (Deemed to be University), Bengaluru, Karantaka, India \\ 2 Department of Physics, GITAM School of Sciences, GITAM (Deemed to be University), Bengaluru, Karantaka, India \\ 3 Department of Humanities \& Sciences, Marri Laxman Reddy Institute of Technology and Management, \\ Hyderabad,Telangana, India \\ * Correspondence : hanumanjunath80@gmail.com;
}

Scopus Author ID 57188956297

Received: 25.04.2020; Revised: 10.05.2020; Accepted: 11.05.2020; Published: 13.05.2020

\begin{abstract}
An electrochemical oxidation of dopamine (DA) and tyrosine (Tyr) by metal oxide (MO) modified electrode where $\mathrm{M}=\mathrm{Cu}$ and $\mathrm{Ni}$ in phosphate buffer solution (PBS), $\mathrm{pH} 7.0$ has been studied by cyclic voltammetry (CV) and differential pulse voltammetry (DPV) techniques. $\mathrm{CuO}$ and $\mathrm{NiO}$ nanoparticles were prepared by sol-gel process and co-precipitation method respectively and their structure, composition and surface morphology were examined by SEM, XRD, FTIR, UV and Raman techniques. A simple drop cast method is employed for the surface modification of graphite electrode to prepare MO modified electrode and it exhibited good electrocatalytic activity towards detection of $\mathrm{DA}$ and Tyr. The present investigation on $\mathrm{CV}$ studies of DA at $\mathrm{CuO}$ modified electrode showed a reversible oxidation process with an anodic peak potential at $+0.249 \mathrm{~V}$ vs. SCE. However, no specific anodic oxidation peak identified with $\mathrm{NiO}$ modified electrode. Subsequent CV studies with Tyr at MO modified electrode $(\mathrm{M}=\mathrm{Cu}, \mathrm{Ni})$ shows an irreversible oxidation process and both modified electrodes exhibited an anodic peak at a potential of $+0.80 \mathrm{~V}$ against very low or no anodic peak currents obtained at bare graphite electrode. Moreover, the $\mathrm{CuO}$ modified electrode (CMG) successfully separated the anodic signals of dopamine (DA), Ascorbic acid (AA) and Tyrosine in their ternary mixture whereas on bare graphite a single, overlapped oxidative peak was observed. In CV studies, the peak potential difference between AA-DA, DA-Tyr and AA-Tyr is $166 \mathrm{mV}, 323 \mathrm{mV}$ and $489 \mathrm{mV}$ respectively and the corresponding peak potential separations are $209 \mathrm{mV}, 400 \mathrm{mV}$ and $609 \mathrm{mV}$ respectively in differential pulse voltammetry (DPV). Owing to good stability, selectivity and simple low cost fabrication method, $\mathrm{CuO}$ modified electrode is found to be well suited for simultaneous determination of DA, AA and Tyr in their ternary mixture. Additionally, NiO modified electrode also shows good sensitivity towards the detection of tyrosine, so it acts as a good electrochemical sensor to assay tyrosine in the biological sample.
\end{abstract}

Keywords: MO modified graphite electrode; Dopamine; Tyrosine; Ascorbic Acid; Drop cast method;Cyclic voltammetry; Differential Pulse voltammetry.

(C) 2020 by the authors. This article is an open access article distributed under the terms and conditions of the Creative Commons Attribution (CC BY) license (https://creativecommons.org/licenses/by/4.0/).

\section{Introduction}

A noteworthy technological change has been noticed over the years in the sensing of neurotransmitters owing to their predominant role as a diagnostic tool in medicine to forecast specific metabolic diseases [1-2]. In mammalian brain tissues, the occurrence of 
neurotransmitters not only meant for a specific metabolic activity but also as biological indicators to identify the state of a disorder or disease [3-4]. It is very clear that a disharmony in the release of neurotransmitters like dopamine and tyrosine always engender for metabolic and neurological disorders [5]. In the family of catecholamine-neuro transmitters, dopamine (DA) has occupied pinnacle position in stating physiological functions belonging to hormonal, renal, neural and cardiovascular systems in the human body. So its role is pivotal and its abnormal levels in the blood are a cause of concern for diseases like Huntington's disease, Schizophrenia and Parkinson's disease etc [6-8]. In addition, tyrosine (Tyr), a precursor of dopamine plays an essential role in causing inborn disorders like Alkpatonuria (AKU), Tyrosinaemia (I, II and III type) and Hawkinsinuria. To envisage type-2 diabetes, liver cancer and obesity the concentration level of tyrosine play a decisive role [9-10].

On contemplating the method of estimation of dopamine and tyrosine, electrochemical methods were phenomenal in spite of a plethora of other analytical techniques available. Portability, accuracy and fast response in sensing, electrochemical methods are better than any other analytical methods which have their own setbacks [11-13].At present, the augment of new materials still continue to be of interest to apply on the surface of graphite electrode with better sensing properties, including conductive polymers, nanoparticles and carbon based materials. More recently, the sensors based on various metal oxide nanoparticles have evinced to be more efficient due to high selectivity, sensitivity, low cost, easy to synthesize in various nanostructures and excellent electro-active nature [14-17]. Such chemically modified electrodes are well suitable in resolving the homogenous structures like dopamine and tyrosine at different electrode potentials though both coexist at low concentrations [18]. So the challenges prevailed even in electrochemical methods like maintaining stability sensitivity and selectivity in the detection of target molecules like dopamine and tyrosine in the presence of other interference molecules [19-23].

In the search of metal oxide nanoparticles, copper (II) oxide $(\mathrm{CuO})$, a p-type of semiconductor with a band gap of 1.2 to $2.2 \mathrm{e} \mathrm{V}$ has been showing countless applications including electrochemical sensors, gas sensors, life aspects, solar energy, batteries and green catalysts [24-27]. The copper oxide nanoparticles can be prepared in various morphological shapes such as nanowires, platelets and spindles [28-29]. In the detection of glucose [30-31] and other biomolecules [32-37], copper oxide nanoparticles were of extremely useful. On the other hand, nickel (II) oxide ( $\mathrm{NiO}$ ) nanoparticles exhibits a band gap of around $3.7 \mathrm{eV}$ and is a p-type semiconductor. Because of low toxicity, good stability and high electrocatalytic property, $\mathrm{NiO}$ nanoparticles attracted the attention of many researchers in the field of electrochemical sensing and lured electrochemists a lot [38-41]. Despite its own limitations, $\mathrm{NiO}$ nanoparticles have been used to sense certain electro-active bio-molecules like dopamine and others, which support the research reports [38-40].

In this study, $\mathrm{CuO}$ and $\mathrm{NiO}$ nanoparticles were prepared by sol-gel process and coprecipitation method respectively and characterized by XRD, UV, IR, Raman and SEM techniques. From the available literature and to the best of the authors knowledge, electrochemical studies on dopamine and tyrosine using $\mathrm{CuO}$ and $\mathrm{NiO}$ nanoparticles are scanty and a comparative study on the electrochemical performance of $\mathrm{CuO}$ and $\mathrm{NiO}$ nanoparticles modified graphite electrode towards oxidation of dopamine and tyrosine is not reported. 


\section{Materials and Methods}

\subsection{Reagent and materials.}

Dopamine, ascorbic acid, copper (II) nitrate, nickel (II) chloride, $\mathrm{NaOH}$, ethanol and liquid paraffin were purchased from Sigma-Aldrich. Potassium chloride, potassium dihydrogen phosphate, dipotassium hydrogen phosphate, tyrosine were purchased from Fischer Scientific Ltd. and used as received. Stock solutions of $0.01 \mathrm{M}$ dopamine, $0.01 \mathrm{M}$ ascorbic acid and $0.002 \mathrm{M}$ tyrosine were prepared freshly using double distilled water. Phosphate buffer solutions

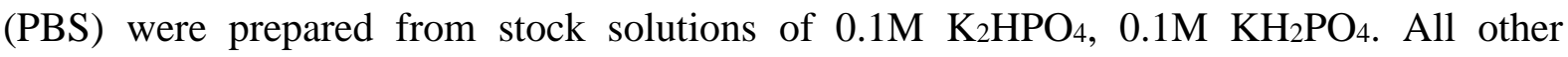
chemicals were of analytical grade and used without further purification.

\subsection{Equipment.}

The prepared $\mathrm{CuO}$ and $\mathrm{NiO}$ nanoparticles were physically characterised by Powder $\mathrm{X}$ Ray Diffraction (XRD) using X'Pert PRO Diffractometer with $\mathrm{Cu} \mathrm{K \alpha}$ radiation of wave length $0.15406 \mathrm{~nm}$. The surface morphology of the synthesised particles of $\mathrm{NiO}$ and $\mathrm{CuO}$ were observed using a scanning electron microscope (SEM) HITACHI S4160. Fourier transforms infrared (FT-IR) spectra and UV-Vis spectra of the material were recorded using Thermo model, Instrument model $\lambda 35$, to determine the functional groups. Raman spectra of the material at room temperature (RT) were obtained using 3D scanning confocal microscope with spectrometer nanofinder-S (SOLAR TII, Ltd.).

\subsection{Electrochemical measurements.}

The electrochemical measurements such as cyclic voltammetry (CV) and differential pulse voltammetry (DPV) were carried out using a potentiostat/galvanostat, VSP, Biologic's instruments, France. A three electrode electrochemical cell consisting of $\mathrm{MO}(\mathrm{M}=\mathrm{Cu}$ or $\mathrm{Ni})$ modified graphite electrode as a working electrode, a platinum wire as auxiliary and a saturated calomel electrode as reference electrode was used for all electrochemical measurements with $0.1 \mathrm{M}$ phosphate buffer solutions (PBS) with $0.1 \mathrm{M} \mathrm{KCl}$ as supporting electrolyte.

\subsection{Synthesis of $M O(M=N i$ and $C u)$ nanoparticles $(N P s)$.}

\subsubsection{Copper oxide NPs.}

$\mathrm{CuO}$ nanoparticles were prepared by sol-gel method which involves reacting two aqueous solutions of $100 \mathrm{ml} 0.1 \mathrm{M}$ of $\mathrm{Cu}\left(\mathrm{NO}_{3}\right)_{2} .3 \mathrm{H}_{2} \mathrm{O}$ and $\mathrm{NaOH} 0.9$ Msolution $\left(\mathrm{pH}=13\right.$ at $25^{\circ}$ C). $0.9 \mathrm{M} \mathrm{NaOH}$ solution was added to $0.1 \mathrm{M}$ of $\mathrm{Cu}\left(\mathrm{NO}_{3}\right)_{2} .3 \mathrm{H}_{2} \mathrm{O}$ solution drop by drop until a blue gel was produced. The obtained gel was washed several times with distilled water until it is free from nitrate ions. It was then centrifuged and dried in air at $60{ }^{\circ} \mathrm{C}$ for $12 \mathrm{hrs}$. This dried gel was separated in several portions and annealed in air for $3 \mathrm{hrs}$ at $250{ }^{\circ} \mathrm{C}$.

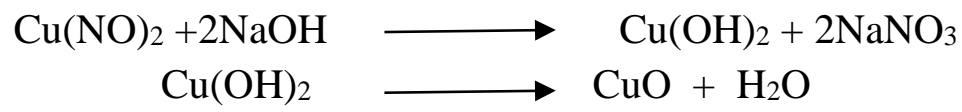




\subsubsection{Nickel oxide NPS.}

Nickel oxide nanoparticles were prepared by co-precipitation method. In atypical procedure, $2.6 \mathrm{~g}$ of nickel(II)chloride was dissolved in $100 \mathrm{ml}$ of de-ionized water. To this, sodium hydroxide (4 g in $100 \mathrm{ml}$ of deionized water ) solution was added drop by drop under constant stirring up to $4 \mathrm{hrs}$. The resultant solution was kept under refluxed at room temperature for $24 \mathrm{hrs}$. The obtained green precipitate was washed with double distilled water and ethanol 5-6 times to remove any possible ionic remnants if formed. The sample was dried by heating at $90^{\circ} \mathrm{C}$. The same is then calcinated at $250^{\circ} \mathrm{C}$ when the greenish sample turned into black color powder.

$$
\mathrm{NiCl}_{2} \cdot 6 \mathrm{H}_{2} \mathrm{O}+\mathrm{H}_{2} \mathrm{O}+2 \mathrm{NaOH} \longrightarrow \mathrm{NiO}+8 \mathrm{H}_{2} \mathrm{O}+2 \mathrm{NaCl}
$$

\subsection{Preparation of $M O(M=N i$ or $\mathrm{Cu})$ modified graphite electrode.}

A Teflon bar with $6 \mathrm{~mm}$ internal diameter was fitted with a spectroscopic grade pure graphite (6mm diameter) purchased from Sigma-Aldrich. The surface of graphite electrode was activated before modification by polishing with emery papers of different grades like 1000 and 800 to get a mirror shining surface. Further, it was cleaned by sonication with double distilled water for 2 minutes. A MO suspension was prepared by mixing $5 \mathrm{mg}$ of MO nanoparticles in $0.1 \mathrm{ml}$ of liquid paraffin and $0.9 \mathrm{ml}$ of water by sonicating the mixture for 30 minutes. The obtained homogenous black suspension of about $10 \mu \mathrm{L}$ was dropped on cleaned surface of graphite electrode and allowed to dry for about $3 \mathrm{hrs}$ at room temperature [41]. The resulting modified electrode acts as a working electrode and from here onwards referred to as $\mathrm{MO} / \mathrm{Gr}$ $(\mathrm{M}=\mathrm{Ni}$ or $\mathrm{Cu})$ modified electrode.

\section{Results and Discussion}

\subsection{Characterization of $M O(M=C u$ and $N i)$ nanoparticles.}

\subsubsection{XRD Studies.}

The XRD pattern of the prepared $\mathrm{CuO}$ and $\mathrm{NiO}$ nanoparticles are shown in Fig.1 (A) and Fig.1 (B). In Fig.1 (A) the appeared diffraction peaks at $2 \theta=32.83,35.53,38.68,48.93$, $53.46,58.18,61.72,66.26,68.23,72.56$ and 75.12 correspond to the lattice planes, (110), (11$1,111),(20-2),(202),(11-3),(022,31-1),(220),(311)$ and $(004,22-2)$ respectively . All peaks can be well indexed to monoclinic symmetry with a space group of $C^{6} 2 h$ and are in consistent with standard (JCPDS file no. 45-0937) data. In Fig. 1(B), XRD of NiO nanoparticles has three distinct peaks at $2 \theta=36.5^{\circ}, 43.5^{\circ}$ and $63^{\circ}$ with peak line broadening indicating nano particle size of $\mathrm{NiO}$ material. The prominent peaks are indexed as (111), (200), (220), (311) and (222) which correlate to face-centered cubic $(F C C)$ structure of $\mathrm{NiO}$ phase and are in good agreement with standard (JCPDS -file: 78-0429, Fm $3 m$ space group) data. The particle size of metal oxide (MO, $\mathrm{M}=\mathrm{Cu}$ and $\mathrm{Ni}$ ) nanoparticles were calculated using Debye-Scherer's formula shown below with k-0.9, Scherrer's constant, $\lambda$ - wavelength of the $\mathrm{Cu}-\mathrm{K} \alpha$ radiation (1.5406 $\AA$ ),

$$
d=\mathrm{K} \lambda /(\beta \cos \theta)
$$

The average particle size of $\mathrm{CuO}$ nanoparticles was found to be $17.3 \mathrm{~nm}$ calculated from $\beta$ - full width at half maximum (FWHM) intensity of 0.5021 from the peak at $\theta-35.6^{0}$. Further, the crystallite size of $\mathrm{NiO}$ nanoparticles was found to be between 3-4 $\mathrm{nm}$ using the 
values of $\beta$ - full width at half maximum (FWHM) intensity, 2.783 from the peak located at $\theta$ $43.3^{0}$.
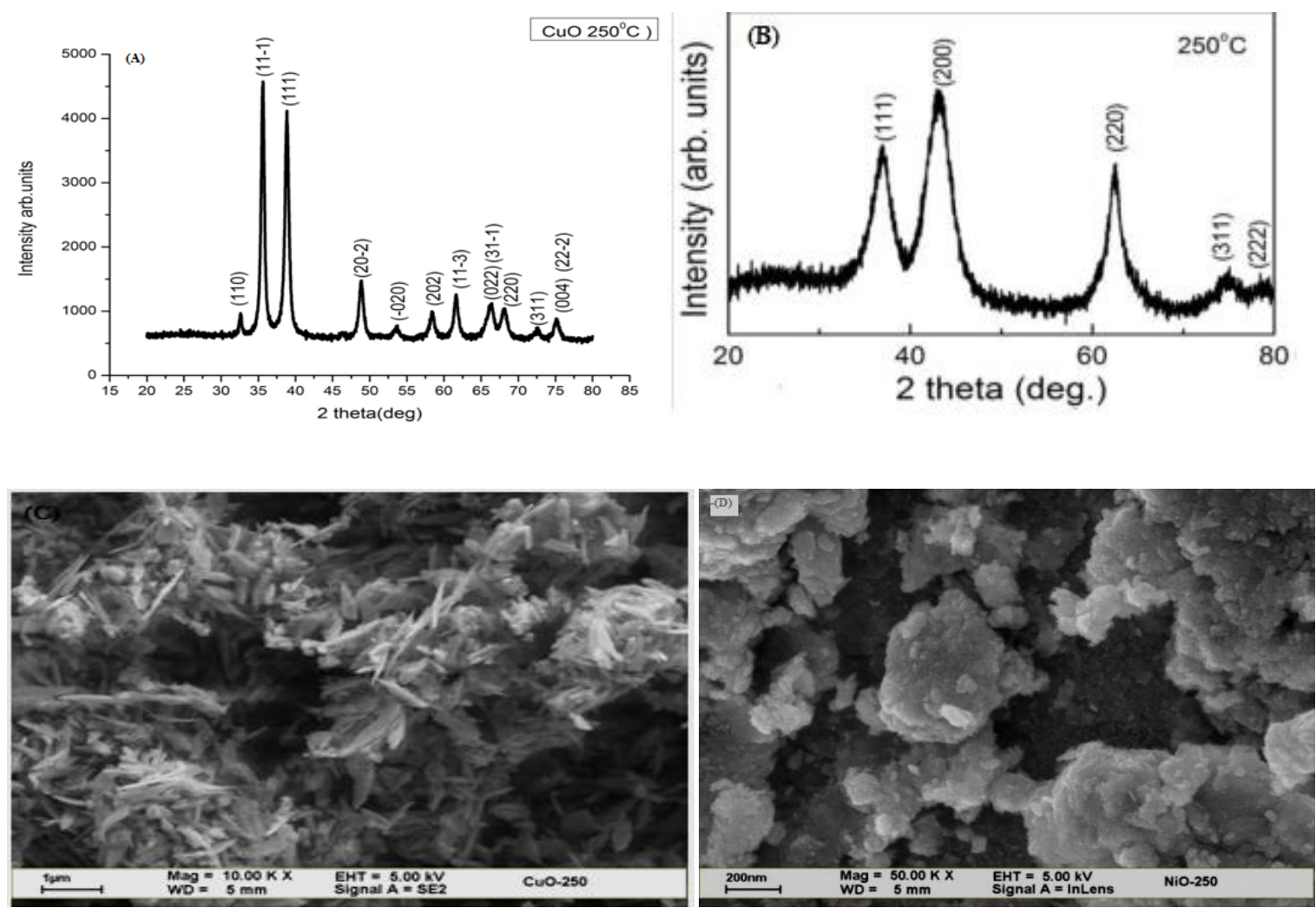

Figure 1. $\mathrm{XRD}$ of , A) $\mathrm{CuO}$ nano particles\&B) $\mathrm{NiO}$ nano particlesand SEM images of, C) $\mathrm{CuO}$ nano particles \& D) $\mathrm{NiO}$ nano particles

\subsubsection{SEM morphological characterisation.}

Fig 1(C) shows the SEM image of $\mathrm{CuO}$ nanoparticles and the surface morphology of the particles show irregular size, agglomerated nanoparticles appearing in sheet or rod like shapes. Such morphology imparts high surface area to the nanomaterial which intern will have high catalytic activity. The average particle size of CuOfrom SEM image is found to be 200 to $500 \mathrm{~nm}$ length and 20-30 nm width. Fig. 1(D) shows the SEM image of NiO nanoparticles having a spherical shape with an average particle size around $19 \mathrm{~nm}$. The formation of ultrafine $\mathrm{NiO}$ nanoparticles reveals that high agglomeration of nanoparticles induces good catalytic activity.

\subsubsection{IR and Raman studies.}

Fig.2 (A) shows the FTIR spectrum of $\mathrm{CuO}$ nanoparticles which exhibit characteristic IR peaks at $523 \mathrm{~cm}^{-1}$ and $1011 \mathrm{~cm}^{-1}$ indicating different modes of bending vibrations of the $\mathrm{Cu}-$ $\mathrm{O}$ bond. The peak at $1639 \mathrm{~cm}^{-1}$ is assigned to stretching vibration of the $\mathrm{Cu}-\mathrm{O}$ bond of copper (II) oxide nanoparticles. The additional IR peaks at $2933 \mathrm{~cm}^{-1}$ and $3432 \mathrm{~cm}^{-1}$ belongs to the symmetric and asymmetric stretching vibration of the $\mathrm{O}-\mathrm{H}$ bond respectively suggesting the presence of traces of water molecules. The FTIR spectrum of NiO nanoparticles is as shown in Fig. 2(B). The prominent peaks at $590 \mathrm{~cm}^{-1}$ and $610 \mathrm{~cm}^{-1}$ belongs to vibrations of Ni-O bond and other additional peaks at $1651 \mathrm{~cm}^{-1}$ and $3635 \mathrm{~cm}^{-1}$ are attributed to $\mathrm{H}-\mathrm{O}-\mathrm{H}$ stretching indicating trace amounts of moisture in the sample. The Raman spectrum of $\mathrm{CuO}$ nanoparticles 
in Fig. 2(C) shows a characteristic peak around $981 \mathrm{~cm}^{-1}$ belonging to stretching mode of $\mathrm{CuO}$ while $\mathrm{NiO}$ nanoparticles in Fig. 2(D) exhibits a distinct peak at around $500 \mathrm{~cm}^{-1}$ related to stretching mode of $\mathrm{NiO}$.
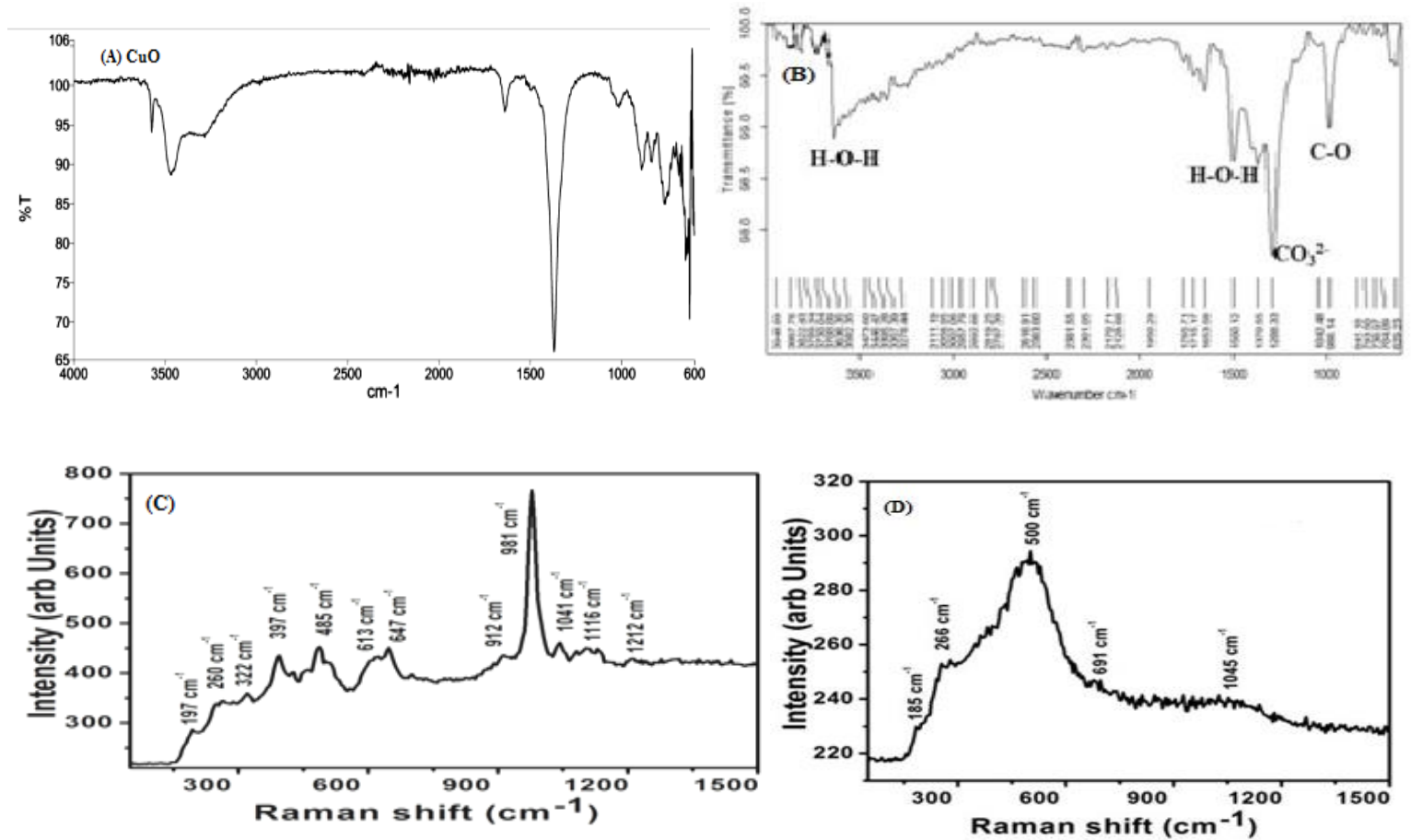

Figure 2. FTIR spectra of, A) $\mathrm{CuO}$ nanoparticles \& B) $\mathrm{NiO}$ nanoparticlesand Raman spectra of C) $\mathrm{CuO}$ nanoparticles \& D) $\mathrm{NiO}$ nanoparticles

\subsection{Electrochemical behavior of $\mathrm{DA}$ and Tyr at $\mathrm{CuO}$ modified graphite electrode( $\mathrm{CMG})$.}

The metal oxide modified electrode was used to study the electrochemical oxidation of DA and Tyr using cyclic voltammetry. The experiments were performed in the presence of $500 \mu \mathrm{M}$ DA and $500 \mu \mathrm{M}$ Tyr individually at the modified electrode in PBS solution, $\mathrm{pH} 7.0$ and results are compared with that on bare graphite electrode.

3.2.1. Electrochemical studies of $\mathrm{DA}$ at the $\mathrm{CuO}$ modified graphite electrode.

Fig. 3 (A) shows the cyclic voltammogram of $500 \mu \mathrm{M}$ DA at bare graphite electrode (a) and at $\mathrm{CMG}$ electrode (b) in PBS ( $\mathrm{pH}=7.0$ ) electrolyte. In PBS solution, $\mathrm{pH} 7.0$ (in the absence of any analyte), the bare graphite electrode exhibits no obvious oxidation and reduction peaks (a) and the $\mathrm{CuO}$ modified electrode shows an anodic peak at $-0.163 \mathrm{~V}$ and a cathodic peak at $0.355 \mathrm{~V}$ corresponding to oxidation $\left(\mathrm{Cu}^{0} / \mathrm{Cu}^{+2}\right)$ and reduction $\left(\mathrm{Cu}^{+2} / \mathrm{Cu}^{0}\right)$ of $\mathrm{CuO}$ nanoparticles respectively in PBS pH 7.0 solution. On the other hand, in the presence of $500 \mu \mathrm{M}$ DA, DA undergoes reversible oxidation and reduction at bare graphite electrode with the oxidation peak located at about $+0.257 \mathrm{~V}$ (c) and at the modified electrode, its oxidation peak is observed at $+0.249 \mathrm{~V}$. In addition, there is significant enhanced of oxidation peak current on the modified electrode indicating better electro catalytic behavior of $\mathrm{CuO}$ nanoparticles towards $\mathrm{DA}$ oxidation. The oxidation peak at $+0.249 \mathrm{~V}$ on the $\mathrm{CV}$ curve of DA at the modified electrode is assigned to the formation of dopaminoquinone $\left(\mathrm{DA}^{+}\right)$(product of dopamine oxidation) and the cathodic peak at $+0.125 \mathrm{~V}$ is assigned to the reduction of $\mathrm{DA}^{+}$to leucodopanoquinone [4243]. Fig 3(B) shows the CV profiles of DA at different concentrations and it is clear from the figure that the oxidation current of DA increases linearly with an increase in concentration at the $\mathrm{CuO}$ modified electrode. 


\subsubsection{Effect of scan rate.}

In order to understand the reversibility of electrocatalytic oxidation reaction of DA at $\mathrm{CuO}$ modified electrode, cyclic voltametric experiments were conducted by varying scan rate from 20 to $200 \mathrm{mV} \mathrm{s}^{-1}$ as shown in Fig 3(C). A plot of $I_{p a}$ vs. V shows a good linear relationship with zero intercept (inset in the figure) and another plot of anodic peak current $\left(I_{p a}\right)$ varies linearly with square root of scan rate $\left(v^{1 / 2}\right)$ (inset in the figure) with zero intercept. From both the plots, it is confirmed that the oxidation of DA at the CMG electrode is a diffusion controlled process. In order to calculate the kinetic parameters, a plot of $E_{p a}$ vs. $\log \mathrm{V}$ (Figure not shown) gives an anodic charge transfer coefficient $(\alpha)$ of 0.73 with slope equal to 2.303RT/(1- $\alpha) \mathrm{n}_{\mathrm{a}} \mathrm{F}$. The calculated Tafel slope, $\mathrm{b}$ for the modified electrode is found to be 0.034 $\mathrm{V} \mathrm{dec}{ }^{-1}$ whichwas less than theoretical value $0.118 \mathrm{~V} \mathrm{dec}^{-1}$ for a one electron transfer process suggesting no adsorption of dopamine occurs on the electrode surface. From Laviron's equation (1) [44-45], electron transfer rate constant $\left(k_{s}\right)$ for this CMG electrode was found to be $0.43 \mathrm{~s}^{-1}$ at $0.05 \mathrm{~V} \mathrm{~s}^{-1}$.

$$
\log k_{s}=\alpha \log (1-\alpha)+(1-\alpha) \log \alpha-\log (\mathrm{RT} / n F \mathrm{n})-\alpha(1-\alpha) \mathrm{nFE} / 2.3 \mathrm{RT}
$$

According to the electron transfer kinetics, for any electron transfer process, higher the rate constant than $0.01 \mathrm{~s}^{-1}$, then the reaction is fast and reversible. Hence the oxidation of DA at CMG electrode is fast, reversible and diffusion controlled with two proton coupled, two electron processes as shown in Fig 4.
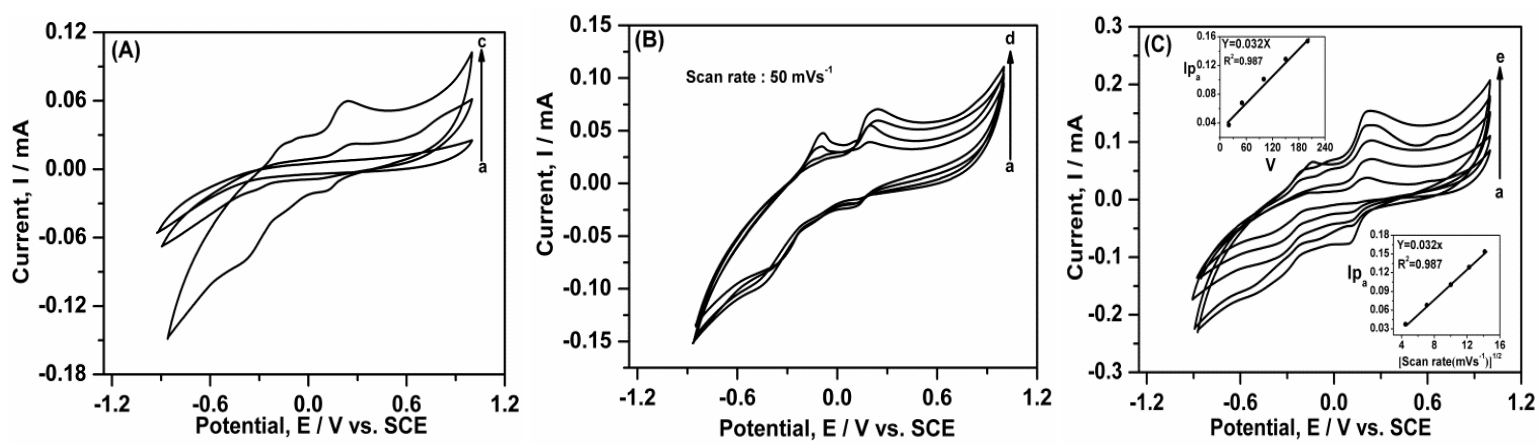

Figure 3. A) Cyclic voltammograms of: A) Bare graphite B) Bare graphite with $250 \mu \mathrm{M}$ DA and $500 \mu \mathrm{M}$ Tyr C) $\mathrm{CMG}$ WITH $250 \mu \mathrm{M}$ DA: Electrolyte solution 0.1M Phosphate buffer solution ( $\mathrm{pH} 7.0)+0.1 \mathrm{M} \mathrm{KCl} \mathrm{B})$

Cyclic voltammograms of DA of various concentrations at CMG electrode: a) $62.5 \mu \mathrm{M} \mathrm{b}) 125 \mu \mathrm{M}$ c) $250 \mu \mathrm{M}$ d) $500 \mu \mathrm{M}$ Scan rate: $50 \mathrm{mV} \mathrm{s}^{-1} \mathrm{C}$ ) Cyclic voltammograms of $500 \mu \mathrm{M}$ DA at CMG electrode at different scan rates a) 20 b) 50 c) 100 c) 150 d) $200 \mathrm{mV} \mathrm{s}^{-1}$ Inset: plots of $I_{p a}$ Vs $v$ and $I_{p a}$ Vs. $v^{1 / 2}$<smiles>Cc1ccc(O)c(O)c1</smiles><smiles>C=CCC1=CC(=O)C(=O)C=C1</smiles>

\section{$+2 \mathrm{H}^{+}+2 \mathrm{e}^{-}$}

Figure 4. Oxidation of Dopamine (two electron process)

\subsection{Electrochemical studies of L-Tyrosine at $\mathrm{CuO}$ modified electrode.}

Fig.5(A) shows the electrochemical behavior of Tyr at the CMG modified electrode. Tyr undergoes irreversible oxidation at the modified electrode with an anodic peak at $0.812 \mathrm{~V}$ with an enhanced peak current compared to that at the bare graphite electrode. The enhancement in the anodic peak current suggests that the $\mathrm{CuO}$ modified electrode shows good 
electro catalytic activity towards Try oxidation. Fig 5(B) shows the CV profile of Tyr at the $\mathrm{CuO}$ modified electrode and it observed that the oxidation current of DA increases linearly with increase in concentration. To understand the effect of scan rate, cyclic voltammetry profiles were recorded at CMG in PBS 7.0 solution containing $250 \mu \mathrm{M}$ tyrosine and are as shown in Fig.5(C). Using Randels- Sevcik equation, a plot of $I_{p a v s .} v^{1 / 2}$ (20 to $200 \mathrm{mV} \mathrm{s}^{-1}$ ) shows good a linear relationship with zero intercept, $I_{p a}=0.0205 v^{1 / 2}$ (Inset in the figure). Thus electrochemical oxidation of Tyr at CMG electrode is diffusion controlled process and exhibits irreversibility which was also confirmed from shifting of anodic peak potential towards a more positive potential.
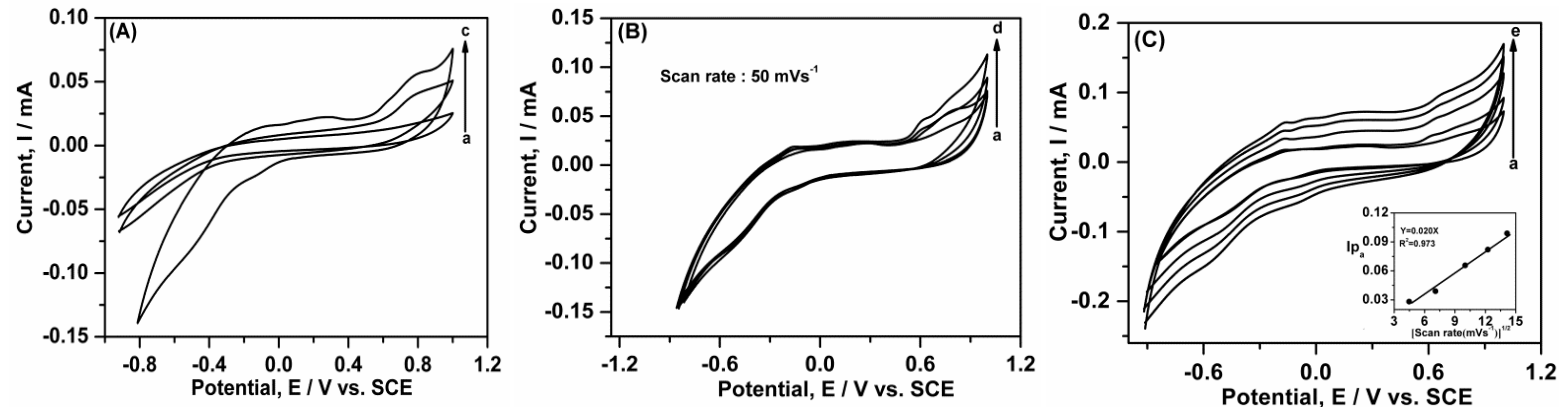

Figure 5. A) Cyclic voltammograms of: A) Bare graphite B) Bare graphite with $500 \mu \mathrm{M}$ Tyr C) CMG with $500 \mu \mathrm{M}$ Tyr: Electrolyte solution 0.1M Phosphate buffer solution ( $\mathrm{pH} 7.0)+0.1 \mathrm{M} \mathrm{KCl} \mathrm{B}$ ) Cyclic voltammograms of Tyr of various concentrations at CMG electrode: a) $250 \mu \mathrm{M}$ b) $500 \mu \mathrm{M}$ c) $750 \mu \mathrm{M}$ d) 1000 $\mu \mathrm{M}$ Scan rate: $50 \mathrm{mV} \mathrm{s}^{-1} \mathrm{C}$ ) Cyclic voltammograms of $250 \mu \mathrm{M}$ Tyr at CMG electrode at different scan rates a) 20 b) 50 c) 100 c) 150 d) $200 \mathrm{mV} \mathrm{s}^{-1}$ Inset: plot of $I_{p a}$ Vs. $v^{1 / 2}$.

\subsection{Simultaneous determination of $D A, A A$ and Tyr using $C u O$ modified graphite electrode.}

Since DA and AA coexist in the biological fluids, interference of one in the determination of others and also in the presence of a very low concentration of tyrosine during their selective determination cannot be ruled out. It is understood that high concentrations of DA and AA may interfere with the detection of Tyr. Further, the poor response of tyrosine and combined response of DA and AA at very close potentials are generally observed on bare electrodes. The CV studies were conducted for ternary mixture of $500 \mu \mathrm{M} \mathrm{DA}, 2 \mathrm{mM}$ AA and $500 \mu \mathrm{M}$ Tyr in PBS buffer solution at bare graphite electrode and $\mathrm{CuO}$ modified graphite electrode and results are as shown in Fig. 6. On bare graphite, there was convergence of oxidation peaks of AA, DA and Tyr was noticed which cannot provide any information about concentration of individual analytes. Conversely, oxidation peaks of AA, DA and Tyr are very well separated from one another and appear at different potentials, $193 \mathrm{mV}, 359 \mathrm{mV}$ and 682 $\mathrm{mV}$ respectively. In addition, an additional peak was observed at $-131 \mathrm{mV}$ which corresponds to $\mathrm{Cu}^{0} / \mathrm{Cu}^{+2}$ redox couple of copper oxide nanoparticles. $\mathrm{CV}$ studies from Fig. 6(A) shows that all the analytes in the ternary mixture are clearly distinguishable and the anodic peak potential differences between AA-DA, DA-Tyr and AA- Tyr were $166 \mathrm{mV}, 323 \mathrm{mV}$ and $489 \mathrm{mV}$ respectively. On the other hand, DPV studies of the same ternary mixture of $500 \mu \mathrm{M}$ DA, 2 mM AA and $500 \mu \mathrm{M}$ Tyr in PBS buffer solution at bare graphite electrode are as shown in Fig. 6(B). From the figure, it is clear that anodic peaks corresponding to AA, DA and Tyr is submerged and appears as broad single peak with a low anodic current at bare graphite (a). On contrary, on $\mathrm{CuO}$ modified graphite electrode(c), the anodic peaks corresponding to AA, DA and Tyr are clearly separated and three distinguishable anodic peaks are observed. The peak potential separations between, AA-DA, DA-Tyr and AA-Tyr in DPV are found to be $209 \mathrm{mV}$, 
$400 \mathrm{mV}$ and $609 \mathrm{mV}$ respectively. From the above discussion, it is clearly proved that the $\mathrm{CuO}$ modified graphite electrode was able to separate the anodic oxidation current signals of DA, AA and Try and exhibits good electro-catalytic activity compared to that of the bare graphite electrode.
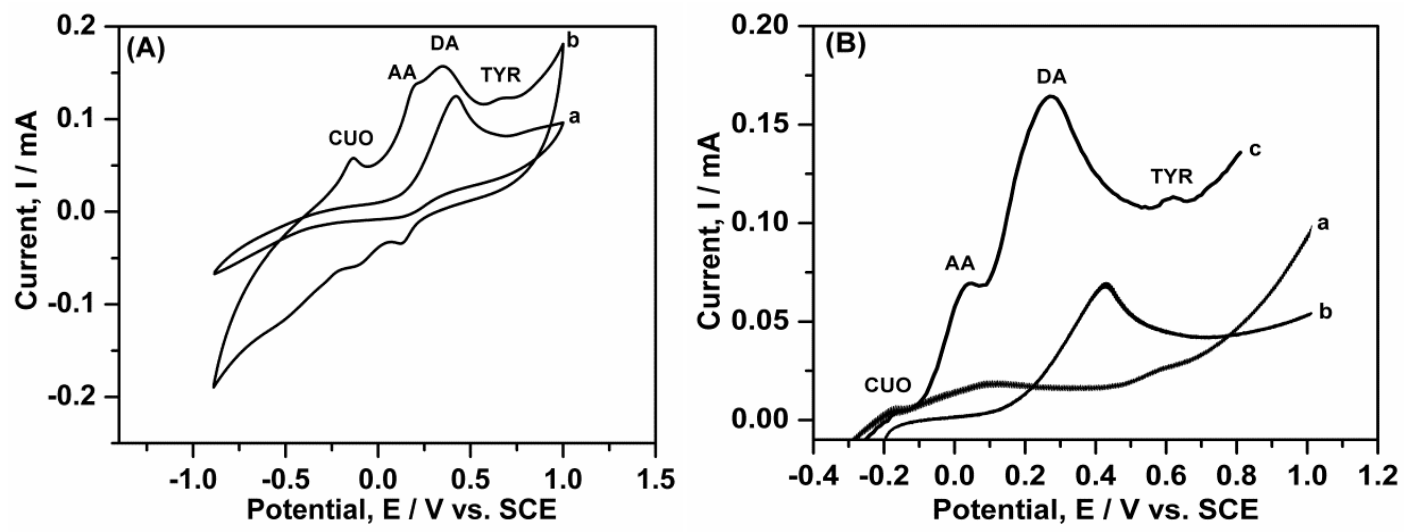

Figure 6. A) Cyclic voltammograms of a) Bare graphite with DA $500 \mu \mathrm{M}, 500 \mu \mathrm{M}$ Tyr and $2 \mathrm{mM}$ AA b) CMG graphite with $500 \mu \mathrm{M}$ DA, $500 \mu \mathrm{M}$ Tyr and $2 \mathrm{mM} \mathrm{AA}$; Scan rate $50 \mathrm{mV} \mathrm{s}^{-1}$ B) Differential pulse voltammogram of a) Bare graphite with $500 \mu \mathrm{M} \mathrm{DA}, 500 \mu \mathrm{M}$ Tyr and $2 \mathrm{mM}$ AA b) CMG electrode with no analyte c) CMG graphite with $500 \mu \mathrm{M}$ DA, $500 \mu \mathrm{M}$ Tyr and $2 \mathrm{mM}$ AA

\subsection{Electrochemical behavior of Tyr at NiO modified graphite electrode (NMG).}

Due to the high electrocatalytic activity of $\mathrm{NiO}$ nanoparticles, electrochemical studies were conducted for the detection of tyrosine using $\mathrm{NiO}$ modified graphite electrode in PBS solution, $\mathrm{pH}$ 7.0. The $\mathrm{CV}$ profiles were recorded at $\mathrm{NiO}$ modified graphite electrode at different concentrations of Tyr in the range of 5 to $400 \mu \mathrm{M}$ in PBS pH 7.0 and are as shown in Fig 7(A). From the figure, it can be seen that the oxidation peak of Tyr appears at $+0.80 \mathrm{~V}$ and the peak current increases with an increase of concentration of tyrosine confirming an excellent electrocatalytic activity of $\mathrm{NiO}$ modified electrode towards oxidation of DA. In order, to understand electron transfer kinetics of oxidation reaction of Tyr at NMG, CV studies were performed with varying scan rate in the range 20 to $200 \mathrm{mVs}^{-1}$ and the results are shown in Fig. 7(B). A plot $I_{p a}$ vs. square root of scan rate, (from Randels-Sevcik equation) shows a good linear relationship with zero intercept, (inset in the figure) indicating the reaction goes through diffusion controlled process rather than charge controlled process.
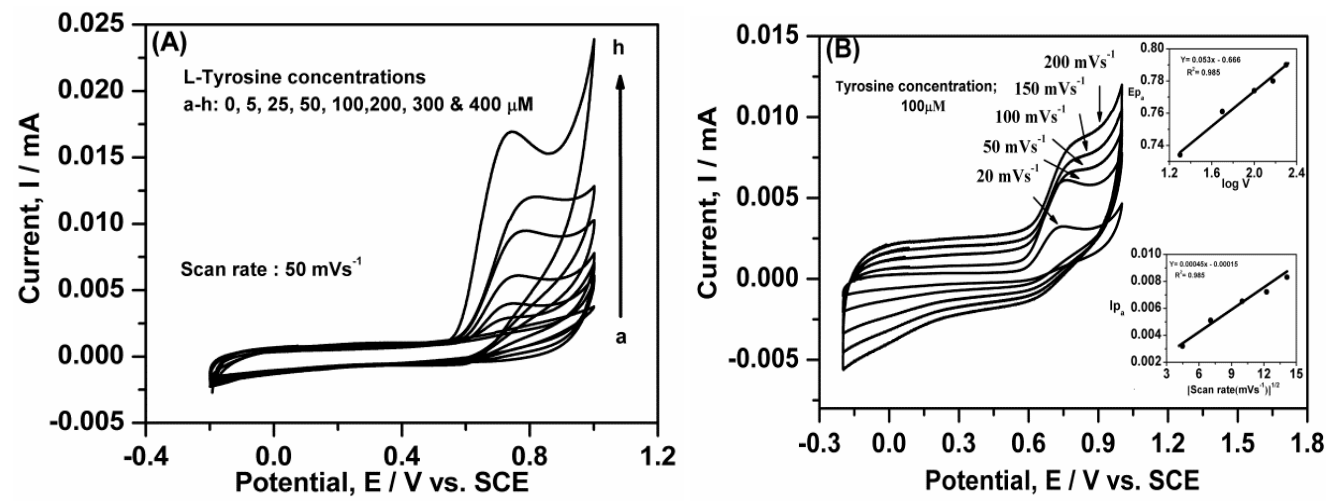

Figure.7. A) Cyclic voltammograms of Tyr of various concentrations at NMG electrode a) 0 b) 5 c) 25 d) 50 e) $100 \mathrm{f}) 200 \mathrm{~g}$ ) $300 \mathrm{~h}) 400 \mu \mathrm{M} 50 \mathrm{mV} \mathrm{s}^{-1}$ B) Cyclic voltammograms of $100 \mu \mathrm{M}$ Tyr at NMG electrode at different scan rates a) 20 b) 50 c) 100 d) 150 e) $200 \mathrm{mVs}^{-1}$ Inset: plots of $I_{p a}$ vs $v$ and $I_{p a}$ vs. $v^{1 / 2}$. 
From Fig 7(B) it is found that anodic peak of Try shifts towards the positive side of potential suggesting irreversibility of electrochemical reaction. The slope of $E_{p a}$ vs. $\log \mathrm{V}$ is equal to $2.303 \mathrm{RT} /(1-\alpha) \mathrm{n}_{\mathrm{a}} \mathrm{F}$ (from inset in the Fig $7(\mathrm{~B})$ ) is used to calculate the charge transfer coefficient, $\alpha$ and was found to be 0.140 for $\mathrm{NiO}$ modified electrode. The calculated Tafel slope, $b$, for the irreversible diffusion controlled process was $0.112 \mathrm{Vdec}^{-1}$ and it is close to the theoretical Tafel value of $0.118 \mathrm{Vdec}^{-1}$ for one electron reaction. Thus the electrochemical oxidation of tyrosine at NMG is a one electron transfer process in accordance with the equation in Fig. 8.

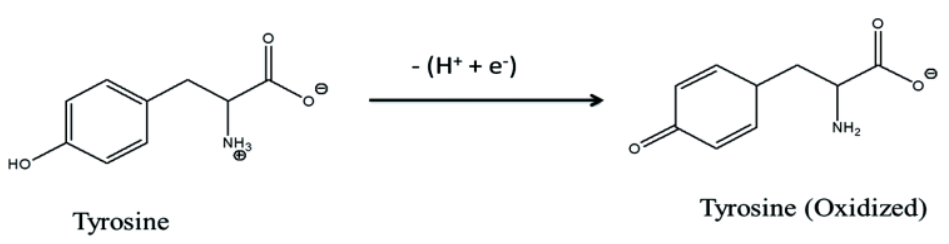

Figure 8. Oxidation of tyrosine (one electron transfer)

\subsection{A comparative electrochemical study of $\mathrm{MO}(\mathrm{M}=\mathrm{Cu}$ and $\mathrm{Ni})$ modified graphite} electrode on dopamine and tyrosine.

A comparative account of the electrochemical performance of $\mathrm{NiO}$ and $\mathrm{CuO}$ modified graphite electrodes towards the electrochemical oxidation of $500 \mu \mathrm{g}$ dopamine and Tyrosine $250 \mu \mathrm{g}$ are as shown in Fig. 9(A) and Fig 9(B) respectively. The evaluated electrochemical parameters from the study are provided in table 1.Taking into consideration of aforementioned electrochemical parameters in table 1 for $\mathrm{CuO}$ and $\mathrm{NiO}$ modified graphite electrodes towards oxidation of dopamine and tyrosine, $\mathrm{CMG}$ shows high catalytic activity and sensing performance than NMG. Despite having a high surface area to volume ratio, $\mathrm{NiO}$ exhibits sheet and charge transfer resistance which decreases the electrical conductivity which leads to poor catalytic or sensing activity [46]. On the other side, due to the high redox potential and low over potential, $\mathrm{CuO}$ oxidize dopamine and tyrosine with high anodic potential and at lower potentials compared to $\mathrm{NiO}$.
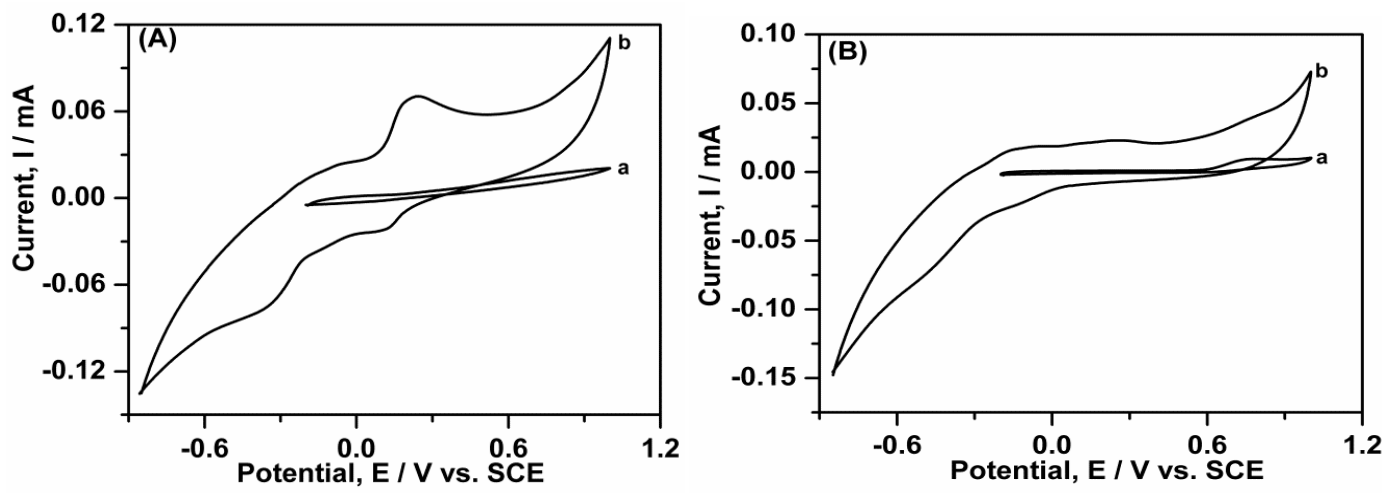

Figure 9. A) Cyclic voltammogram of $500 \mu \mathrm{M}$ DA at a) NMG electrode b) CMG electrode B) Cyclic voltammogram of $250 \mu \mathrm{M}$ Tyr at a) NMG electrode b) CMG electrode $50 \mathrm{mV} \mathrm{s}$.

\subsection{Stability and Reproducibility.}

The stability and reproducibility of $\mathrm{NiO}$ and $\mathrm{CuO}$ modified graphite electrodes were evaluated in separate experiments by measuring their cyclic voltammetry response upon storing for 1-4 weeks.. The modified electrodes were used for the selective detection of $500 \mu \mathrm{M}$ DA in presence of $500 \mu \mathrm{M}$ Tyr and $2 \mathrm{mM}$ AA in PBS pH 7.0. The $\mathrm{CuO}$ modified graphite electrode could distinguish the (Figures not shown) oxidation peaks of DA, AA and Tyr in their ternary 
mixture and shows good response to the selective determination of DA retaining 93, 90, 86 and $82 \%$ of its initial current response when stored for 1,2,3 and 4 weeks respectively. To ensure the reproducibility of the results, experiments were performed with the same $\mathrm{CuO}$ modified electrode for repeated measurement of $100 \mu \mathrm{M}$ DA using chronoamperommetry. After each measurement the modified electrode was washed in PBS pH 7.0 and transferred into another standard solution of $100 \mu \mathrm{M}$ DA to record its oxidation peak current. It is found that the modified electrode lost $8.9 \%$ of initial amperometric response after 15 repeated measurements at a constant dopamine concentration of $100 \mu \mathrm{M}$ and the step potential applied was $500 \mathrm{mV}$. Another experiment was conducted with a single modified electrode and the standard deviation for 10 successive scans was less than 5\% in PBS pH 7.0 solution containing $20 \mathrm{mM}$ DA. This indicates the excellent reproducibility of the $\mathrm{CuO}$ modified electrode. On the other hand, under similar experimental conditions, $\mathrm{NiO}$ modified graphite electrode retained $92,89,85$ and $80 \%$ of its initial current response when stored for 1,2,3 and 4 weeks respectively for the oxidation of $100 \mu \mathrm{M}$ DA. NiO modified electrode lost $10.1 \%$ of initial amperometric response after 15 repeated measurements at a constant dopamine concentration of $100 \mu \mathrm{M}$ and standard deviation for successive scan at a constant concentration of $20 \mathrm{mM}$ DA was less than $7 \%$.

Table 1. Electrochemical parameters on $\mathrm{MO}(\mathrm{M}=\mathrm{Cu}$ and Ni) modified graphite electrode on detection of DA and Tyr.

\begin{tabular}{|c|c|c|c|c|}
\hline \multirow{2}{*}{$\begin{array}{l}\text { Analyte } \\
\text { Electrode }\end{array}$} & \multicolumn{2}{|c|}{ Dopamine-500 $\mu \mathrm{M}$} & \multicolumn{2}{|c|}{ Tyrosine $-250 \mu \mathrm{M}$} \\
\hline & $I_{P a}(\mathrm{~mA})$ & $E_{p a}(\mathrm{~V})$ & $I_{P a}(\mathrm{~mA})$ & $E_{p a}(\mathrm{~V})$ \\
\hline $\mathrm{CMG}$ & +0.07019 & +0.229 & +0.0416 & +0.80 \\
\hline NMG & $\begin{array}{l}\text { No specifi } \\
\text { identified }\end{array}$ & ic peaks were & +0.0094 & +0.80 \\
\hline
\end{tabular}

\section{Conclusions}

Copper oxide nanoparticles prepared by sol-gel method were sucecesfully used for the fabrication of $\mathrm{CuO}$ modified graphite electrode which exhibitedgood electrocatalytic activity towards oxidation of AA, DA and Tyr. Cyclic voltammetry and differential pulse voltammetry studies revealed that oxidation peaks of DA, AA and Tyr are very well separated with high current sensitivity and good stability, particularly for DA. On the other hand, $\mathrm{NiO}$ modified electrode displays poor activity towards dopamine but shows good sensitivity towards the determination of tyrosine. Among, the two metal oxides used for the determination of DA, the $\mathrm{CuO}$ modified electrode shows high catalytic activity. For Tyr, NiO modified graphite electrode is found to be having good electrocatalytic activity. No electrode fouling was observed upon electro-oxidation of DA in the presence of Tyr or high concentration of AA at the $\mathrm{CuO}$ modified graphite electrode.Finally, $\mathrm{CuO}$ modified electrode demonstrated remarkarable sensing activity towards multianalyte mixture of DA, AA and Tyr.

\section{Funding}

This research was funded by Science and Engineering Research Board-Department of Science and Technology (SERB-DST), grant number ECR/2016/000644.

\section{Acknowledgments}

Authors are grateful to the Management of GITAM (Deemed to be University), Bangaluru Campus, India. 


\section{Conflicts of Interest}

\section{The authors declare no conflict of interest.}

\section{References}

1. Choudhury,A.; Tripti, S.; Praveena, L.R.; Banerjee, A.K.; Indrajeet, C.; Arun Kumar, R.; Neelima, A. Neurochemicals, behaviours and psychiatric perspectives of neurological diseases. Neuropsychiatry 2018 , 8, 395-424, https://doi.org/10.4172/Neuropsychiatry.1000361.

2. Bo, S.; Edward, S. Recent Advances in the Detection of Neurotransmitters. Chemosensors 2018, 6, 1-24, https://doi.org/10.3390/chemosensors6010001.

3. Dalley, J.W.; Roiser, J.P. Dopamine, serotonin and impulsivity. Neuroscience 2012, 215, 42-58, https://doi.org/10.1016/j.neuroscience.2012.03.065.

4. Marianne O.K.; Daniella, S.B.; Ariel, R.C.; David, N.H.; Jackson, C.B.; Ricardo, G.C. Dopamine: Functions, Signaling, and Association with Neurological Diseases. Cellular and Molecular Neurobiology 2019, 39, 31-59,https://doi.org/10.1007/s10571-018-0632-3.

5. Kesby, J.P.; Eyles,D.W.; McGrath,J.J.;Scott, J.G. Dopamine, psychosis and schizophrenia: the widening gap between basic and clinical neuroscience. Transl. Psychiatry2018, 8,https://doi.org/10.1038/s41398-0170071-9.

6. Kang, Y.J.;Cutler, E.G.; Cho, H. Therapeutic nanoplatforms and delivery strategies for neurological disorders. Nano Converg 2018, 5,https://doi.org/10.1186/s40580-018-0168-8.

7. Kapalka, G. Substances Involved in Neurotransmission. In:Nutritional and Herbal Therapies for Children and Adolescents.1st Ed., Academic Press is an imprint of Elsevier, London, UK,Chapter 4, 2010; pp. 7499,https://doi.org/10.1016/C2009-0-01890-X.

8. Heiko, B.; Sabine,J.K.; Birgit, A.; Thomas, O. Inherited Disorders of Neurotransmitters: Classification and Practical Approaches for Diagnosis and Treatment. Neuropediatrics 2019, 50, 2-14, https://doi.org/10.1055/s-0038-1673630.

9. Ferguson, A.A.; Roy,S.; Kaitlyn, N. K.; Yongsoon, K.; Dumas, K.J.; Ritov, V.B.; Matern, D.; Patrick J.H.; Fisher, A.L.TATN-1 Mutations Reveal a Novel Role for Tyrosine as a Metabolic Signal That Influences Developmental Decisions and Longevity in caenorhabditis elegans. PLOS Genetics 2013, 9, 1-22, https://doi.org/10.1371/journal.pgen.1004020.

10. Mohorko, N.; Petelin, A.; Jurdana, M.; Gianni, B.; PraDnikar, Z.J. Elevated Serum Levels of Cysteine and Tyrosine: Early Biomarkers in Asymptomatic Adults at Increased Risk of Developing Metabolic Syndrome.BioMed Research International 2015,2015,1-14, http://dx.doi.org/10.1155/2015/418681.

11. Zahra, T.A.; Oana, H.; Cecilia, C.; Mohammad, M.A.; Giovanna, M. Latest Trends in Electrochemical Sensors for Neurotransmitters: A Review. Sensors 2019, 19, 1-30, https://doi.org/10.3390/s19092037.

12. Govindhan, M.; Manickam, S.; Vellaichamy, G. Electrochemical sensor and biosensor platforms based on advanced nanomaterials for biological and biomedical applications. Biosensors and Bioelectronics 2018, 103, 113-129, https://doi.org/10.1016/j.bios.2017.12.031.

13. José, A.R.; Paula, M.V.F.; Carlos, M P.; Silva, F. Electrochemical Sensors and Biosensors for Determination of Catecholamine Neurotransmitters: a Review. Talanta 2016, 160,1-87, http://dx.doi.org/10.1016/j.talanta.2016.06.066.

14. Sara, A.A.; Mahmoud, A.H.; Aisha, A.G.; Anish, K. Composite Material-Based Conducting Polymers for Electrochemical Sensor Applications: a Mini Review. BioNanoSci. 2020, 10, 351-364, https://doi.org/10.1007/s12668-019-00708-X.

15. Cheng, Y.; Madelaine, E.D.; Poojan, P.B.; Jill, V. Recent trends in carbon nanomaterial-based electrochemical sensors for biomolecules: A review. Analytica Chimica Acta 2015, 887, 17-37, https://doi.org/10.1016/j.aca.2015.05.049.

16. Wan, Q.L.; Zhiqiang, G. Metal oxide nannoparticles in electroanalysis. Electroanalysis 2015, 27, 1-18, https://doi.org/10.1002/elan.201500024.

17. Manjunatha, H.; Nagaraju, D.H.; Suresh, G.S.; Venkatesha, T.V. Detection of Uric Acid in the Presence of Dopamine and High Concentration of Ascorbic Acid Using PDDA Modified Graphite Electrode. Electroanalysis 2009, 21, 2198-2206, https://doi.org/10.1002/elan.200904662.

18. Muhammad, S.; Mazen, K.N; Muhammad, M.; Abdulnaser, A.; Shehzada, M.S.J.; Chanbasha, B. Chemically modified electrodes for electrochemical detection of dopamine in presence of uric acid and ascorbic acid: A review. Trends in Analytical Chemistry 2015, 76, 15-26, https://doi.org/10.1016/j.trac.2015.09.006.

19. Intan, R.S.; Novi, A.; Tae, Kim, H. Nanomaterial-modified Hybrid Platforms for Precise Electrochemical Detection of Dopamine.BioChip J. 2019, 13, 20-29, https://doi.org/10.1007/s13206-019-3106-X.

20. Yingchun, L.; Rongyan, H.; Yan, N.; Fei, L. Paper-Based Electrochemical Biosensors for Point-of-Care Testing of Neurotransmitters. Journal of Analysis and Testing 2019, 3, 19-36, https://doi.org/10.1007/s41664-019-00085-0. 
21. Krystyna, J.; Pawel, K. New trends in the electrochemical sensing of dopamine. Anal Bioanal Chem. 2013,405, 3753-3771, https://doi.org/10.1007/s00216-012-6578-2.

22. Mathieu, O.; Jessy, M.; Niyonambaza, S.D.; Miled, A.; Elodie, B. Electrochemical Detection of Dopamine Based on Functionalized Electrodes. Coatings 2019, 9, 496, https://doi.org/10.3390/coatings9080496.

23. Hadi, B.; Mohadeseh, S.; Somayeh, T.Different Electrochemical Sensors for Determination of Dopamine as Neurotransmitter in Mixed and Clinical Samples: A Review. Anal. Bioanal. Chem. Res 2019, 6, 8196, https://doi.org/10.22036/ABCR.2018.142219.1229.

24. Zhang, H.; Zhu, Q.; Zhang, Y. One-pot synthesis and hierarchical assembly of hollow $\mathrm{Cu}_{2} \mathrm{O}$ microspheres with nanocrystals-composed porous multishell and their gas-sensingproperties. Adv Funct Mater 2007, 17, 2766-2771, https://doi.org/10.1002/adfm.200601146.

25. Tarascon, J.M.; Poizot, P.; Laruelle, S. Nano-sized transition-metal oxides as negative-electrode materials for lithium-ion batteries. Nature 2000, 407, 496-499, https://doi.org/10.1038/35035045.

26. Zhang, J.; Liu, J.; Peng, Q. Nearly monodisperse $\mathrm{Cu}_{2} \mathrm{O}$ and $\mathrm{CuO}$ nanospheres: preparation and applications for sensitive gas sensors. Chem Mater 2006,18, 867-871, https://doi.org/10.1021/cm052256f.

27. Bayoumy, A.M; Elhaes, H; Osman, O; Kholmurodov, K.T; Hussein. T; Ibrahim, M.A. Effect of nano metal oxides on heme molecule: molecular and biomolecular approaches. Biointerface Res. Appl. Chem. 2020, 10, 4837 - 4845, https://doi.org/10.33263/BRIAC101.837845.

28. Zhang, X.; Wang, G.; Liu, X. Different CuO nanostructures: synthesis, characterization, and applications for glucose sensors. J Phys Chem C 2008, 112, 16845-16849, https://doi.org/10.1021/jp806985k.

29. Shafiee, M.R.M; Kargar, M. Preparation of aryl sulfonamides using CuO nanoparticles prepared in extractive rosmarinus officinalis leaves media, Biointerface Res. Appl. Chem. 2016, 6, 1257-1262.

30. Yazid, S.N.A.M.; Illyas, M. I.; Suriani, A. B.; Norhayati, H.;Sazeli, A G.A Review of Glucose Biosensors Based on Graphene/Metal Oxide Nanomaterials. Analytical Letters 2014, 47,1821-1834, https://doi.org/10.1080/00032719.2014.888731.

31. Taher, A.; Shabnam, M. A Nafion-free nonenzymatic amperometric glucosesensor based on copper oxide nanoparticles-graphene nanocomposite. Sensors and Actuators B: Chemical 2014,198, 438-447, https://doi.org/10.1016/j.snb.2014.03.049.

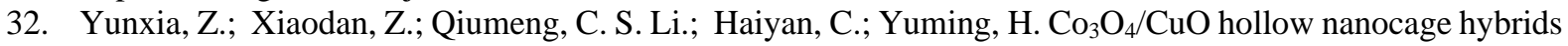
with high oxidase-like activity for biosensing of dopamine. Materials Science \& Engineering C 2019, 94, 858-866, https://doi.org/10.1016/j.msec.2018.10.038.

33. Huang, Y.; Tan, Y.; Feng, C.; Wang, S.; Wu,H.; Zhang, G. Synthesis of $\mathrm{CuO} / \mathrm{g}-\mathrm{C}_{3} \mathrm{~N}_{4}$ composites, and their application to voltammetric sensing of glucose and dopamine.Microchim Acta 2019,186, https://doi.org/10.1007/s00604-018-3120-z.

34. Felixa, S.; Santhosh, C.; Nirmala, G.A.CuO-MWCNTS for Enzyme-Less Electrochemical Detection of Glucose and Dopamine.ECS Transactions 2017, 77, 1847-1857, https://doi.org/10.1149/07711.1847ecst.

35. Baloach, Q.; Ayman, N.; Aneela, T.; Sirajuddin; Syed, T.H.S.; Tayyaba, S.; Munazza, A.; Willander, M.; Zafar, H.I. An amperometric sensitive dopamine biosensor based on novel copper oxide nanostructures, Microsystem Technologies 2017, 23,1229-1235, https://doi.org/10.1007/s00542-015-2805-z.

36. Hulya, O.D.; Bingul, K.U.; Emir, C.; Mesut, E. Simultaneous electrochemical detection of ascorbic acid and dopamine on $\mathrm{Cu}_{2} \mathrm{O} / \mathrm{CuO} /$ electrochemically reduced graphene oxide $\left(\mathrm{Cu}_{\mathrm{x}} \mathrm{O} / \mathrm{ERGO}\right)$ nanocomposite-modified electrode. Microchemical Journal 2019,150, https://doi.org/10.1016/j.microc.2019.104157.

37. Wenxiu, G.; Miaomiao,W.X.M.; Yuru, W.; Lei, L.; Wenshui, X. A facile sensitive L-tyrosine electrochemical sensor based on a coupled $\mathrm{CuO} / \mathrm{Cu}_{2} \mathrm{O}$ nanoparticles and multi-walled carbon nanotubes nanocomposite film. Anal. Methods 2015, 7, 1313-1320, https://doi.org/10.1039/C4AY01925C.

38. Asghar, P.; Akbarzadeh-Torbati, N.; Beitollahi, H. Rapid and Sensitive Electrochemical Monitoring of Tyrosine Using NiO Nanoparticles Modified Graphite Screen Printed Electrode. Int. J. Electrochem. Sci. 2019, 14, 1556 - 1565, https://doi.org/10.20964/2019.02.42.

39. Faezeh, S-F; Roushani, M. Architecting of a biodevice based on a screen-printed carbon electrode modified with the NiO NP nanolayer and aptamer in BCM-7 detection. Colloids and Surfaces B: Biointerfaces 2020, 190,110932, https://doi.org/10.1016/j.colsurfb.2020.110932.

40. Hong, Y.Y.; Zhang, H.J.; Huang, S.; Gao, X.; Shan, S.S.; Wang, Z.; Wang, W.Q.; GuaN, E.H. A novel nonenzymatic dopamine sensors based on NiO-reduced graphene oxide hybrid nanosheets. Journal of Materials Science: Materials in Electronics. 2019, 30, 5000-5007,https://doi.org/10.1007/s10854-019-00796-1.

41. Anuprathap, M.U.; Srivastava, R. Synthesis of $\mathrm{NiCo}_{2} \mathrm{O}_{4}$ and its application in the electrocatalytic oxidation of methanol. NanoEnergy 2013,2,1046-1053,https://doi.org/10.1016/j.nanoen.2013.04.003.

42. Valenzuela, M.V.; Huerta, F.; Morallón, E.; Montilla,F. Affinity of Electrochemically Deposited Sol-Gel Silica Films towards Catecholamine Neurotransmitters. Sensors 2019, 19, 868,115,https://doi.org/10.3390/s19040868.

43. Fayemi, O.E.; Adekunle, A.S.; Kumara Swamy, B.E.; Ebenso, E.E. Electrochemical sensor for the detection of dopamine in real samples using polyaniline/ $\mathrm{NiO}, \mathrm{ZnO}$, and $\mathrm{Fe} 3 \mathrm{O} 4$ nanocomposites on glassy carbon electrode. Journal of Electroanalytical Chemistry 2018, 818, 236-249, https://doi.org/10.1016/j.jelechem.2018.02.027. 
44. Bard, A.J.; Faulkner, L.R. Electrochemical Methods, Fundamentals and Applications. 2nd Ed. Wiley, New York. 2006.

45. Laviron, E. General expression of the linear potential sweep voltammogram in the case of diffusionless electrochemical systems. J. Electroanal. Chem. Interfacia Electrochem. 1979, 101, 19-28, https://doi.org/10.1016/S0022-0728(79)80075-3.

46. George, J.M.; Arun, A.; Mathew, B. Metal oxide nanoparticles in electrochemical sensing and biosensing: a review.Microchim Acta 2018, 185,https://doi.org/10.1007/s00604-018-2894-3. 